Wright State University

CORE Scholar

Physics Faculty Publications

Physics

1996

\title{
Wet Chemical Digital Etching of GaAs at Room Temperature
}

Gregory C. DeSalvo

Christopher A. Bozada

John L. Ebel

David C. Look

Wright State University - Main Campus, david.look@wright.edu

John P. Barrette

See next page for additional authors

Follow this and additional works at: https://corescholar.libraries.wright.edu/physics

Part of the Physics Commons

\section{Repository Citation}

DeSalvo, G. C., Bozada, C. A., Ebel, J. L., Look, D. C., Barrette, J. P., Cerny, C. L., Dettmer, R. W., Gillespie, J. K., Havasy, C. K., Jenkins, T. J., Nakano, K., Pettiford, C. I., Quach, T. K., Sewell, J. S., \& Via, G. D. (1996).

Wet Chemical Digital Etching of GaAs at Room Temperature. Journal of The Electrochemical Society, 143 (11), 3652-3656.

https://corescholar.libraries.wright.edu/physics/682

This Article is brought to you for free and open access by the Physics at CORE Scholar. It has been accepted for inclusion in Physics Faculty Publications by an authorized administrator of CORE Scholar. For more information, please contact library-corescholar@wright.edu. 


\section{Authors}

Gregory C. DeSalvo, Christopher A. Bozada, John L. Ebel, David C. Look, John P. Barrette, Charles L. A. Cerny, Ross W. Dettmer, James K. Gillespie, Charles K. Havasy, Thomas J. Jenkins, Kenichi Nakano, Carl I. Pettiford, Tony K. Quach, James S. Sewell, and G. David Via 


\section{Wet Chemical Digital Etching of GaAs at Room Temperature}

Gregory C. DeSalvo, Christopher A. Bozada, John L. Ebel, David C. Look, John P. Barrette, Charles L. A. Cerny, Ross W. Dettmer, James K. Gillespie, Charles K. Havasy, Thomas J. Jenkins, Kenichi Nakano, Carl I. Pettiford, Tony K. Quach, James S. Sewell and G. David Via

J. Electrochem. Soc. 1996, Volume 143, Issue 11, Pages 3652-3656. doi: $10.1149 / 1.1837266$

Email alerting Receive free email alerts when new articles cite this article - sign up service in the box at the top right corner of the article or click here

To subscribe to Journal of The Electrochemical Society go to: http://jes.ecsdl.org/subscriptions

(C) 1996 ECS - The Electrochemical Society 


\title{
Wet Chemical Digital Etching of GaAs at Room Temperature
}

\author{
Gregory C. DeSalvo, Christopher A. Bozada, John L. Ebel, David C. Look, John P. Barrette, \\ Charles L. A. Cerny, Ross W. Dettmer, James K. Gillespie, Charles K. Havasy, Thomas J. Jenkins, \\ Kenichi Nakano, Carl I. Peltiford, Tony K. Quach, James S. Sewell, and G. David Via'
}

Electron Devices Division, Avionics Directorate, Wright Laboratory,
Wright-Patterson Air Force Base, Ohio 45433-7322, USA

\section{ABSTRACT}

A new room temperature wet chemical digital etching technique for GaAs is presented which uses hydrogen peroxide and an acid in a two-step etching process to remove GaAs in approximately $15 \AA$ increments. In the first step, GaAs is oxidized by $30 \%$ hydrogen peroxide to form an oxide layer that is diffusion limited to a thickness of 14 to $17 \AA$ for time periods from 15 to $120 \mathrm{~s}$. The second step removes this oxide layer with an acid that does not attack unoxidized GaAs. These steps are repeated in succession until the desired etch depth is obtained. Experimental results are presented for this digital etching technique demonstrating the etch rate and process invariability with respect to hydrogen peroxide and acid exposure times.

\section{Introduction}

Modern growth techniques such as molecular beam epitaxy (MBE) and metallorganic chemical vapor deposition (MOCVD) have demonstrated the ability to grow semiconductor layers with atomic layer precision, controllable material mole fractions, and precise dopant concentrations. This controllability allows for the growth of material structures having optimum device performance as determined by device theory and modeling. However, process fabrication techniques capable of removing material with atomic precision (i.e., within several atomic monolayers) need to be developed to obtain the full benefits of these optimum structures. Because the digital etching technique removes several atomic layers of material in a controllable fashion, it may provide the etching necessary to fabricate optimum devices. Such an etching process would be useful in the shallow etching needed for gate recessing of GaAs based field effect transistors such as metal semiconductor field effect transistors (MESFET), high electron mobility transistors (HEMT), and pseudomorphic high electron mobility transistors (pHEMT) and for fabricating quantum wires. ${ }^{1-3}$ In general, the digital etching technique consists of a two-step chemical process to remove a fixed thickness of material. Repetition of this two-step process is used to obtain a desired etch depth in integral multiples of the depth achieved by a single digital etch cycle. The first step of a digital etch cycle uses a chemical reaction to form a thin layer of a new molecular compound at the semiconductor surface. Because this chemical reaction is diffusion limited, the thin layer formed will have a constant thickness for each cycle. In the second step, another chemical reaction is used to selectively remove the newly formed compound layer from the surface without affecting the unreacted semiconductor material underneath.

Earlier research into digital etching of GaAs has used various techniques such as (i) reactive ion etching (RIE) using $\mathrm{Cl}_{2}$ gas to form $\mathrm{GaCl}_{3}$ and $\mathrm{AsCl}_{3}$ compounds which are then removed by low energy electrons, ${ }^{4-8} \mathrm{Ar}$ ions, ${ }^{4-9}$ an ArF laser, ${ }^{10}$ a $\mathrm{KrF}$ laser, ${ }^{11}$ or by thermal etching above $290^{\circ} \mathrm{C},{ }^{11}$ (ii) MBE using a molecular beam of Se to form a monolayer of $\mathrm{Ga}_{2} \mathrm{Se}_{3}$ on the surface, which is removed using a tomic hydrogen $\left(\mathrm{H}^{*}\right),{ }^{12}$ and (iii) anodic oxidation of $\mathrm{GaAs}$, forming $\mathrm{Ga}_{2} \mathrm{O}_{3}$ and other oxide compounds to a fixed depth, which are then removed with a wet chemical etchant. $^{13}$

This work investigates the use of wet chemicals to perform both digital etching steps for GaAs. The basic process consists of using hydrogen peroxide $\left(30 \% \mathrm{H}_{2} \mathrm{O}_{2}\right)$ as the oxidizing agent to form GaAs-oxide compounds at the GaAs surface (oxidation step), that are then removed using an acid (etching step). This simple wet etching technique

a These authors are with the University Research Center of Wright State University at Wright Laboratory. uses standard device fabrication chemicals and provides an economical and controllable etch with etch depths of approximately $15 \AA$. As in normal device fabrication, a photoresist mask can be used with this digital etching process to pattern the etching. Also, wet chemical digital etching does not require high vacuum nor does it heat the wafer as has been reported for $\mathrm{RIE}^{8,11}$ and required by MBE $\left(450\right.$ to $\left.500^{\circ} \mathrm{C}\right) .^{12}$ This process does not require an ohmic contact or a conducting layer/substrate as does anodic oxidation. Finally, wet chemical digital etching has the ability to save processing time since it does not require the use and preparation of specialized equipment (RIE, MBE, or anodic oxidation system).

\section{Wet Chemical Digital Etching}

Standard wet chemical etching of III- $V$ semiconductors occurs by oxidizing the semiconductor surface and etching the oxide. Typically this is achieved by submerging the semiconductors in a liquid mixture consisting of an oxidizing agent and a complexing (oxide etching) agent. ${ }^{14}$ Therefore, the oxidation and etching occur simultaneously, resulting in an etch depth dependent on the length of time the semiconductor is exposed to the etchant. Digital etching separates the oxidation and oxide etching chemical reactions so that each reaction is independent of each other, and etching occurs by sequential application of the reactants. Because the oxidation chemical reaction (first step) is self-limiting, the etch depth is no longer dependent on the etch time, but is dependent on the number of etching cycles.

In the wet chemical digital etching process the thickness of the material removed during one cycle is determined by the amount of GaAs consumed in the oxidation step. An essential component in wet chemical digital etching is to developed a diffusion limited chemical reaction at the surface such that the thickness of the new molecular compound formed remains relatively constant over a short time frame (minutes). The self-limiting thickness is important to the digital etching process because it results in an effective etch depth that is not proportional to time, but is constant for the time frame desired. GaAs oxidation has been extensively studied and is a diffusion limited process. ${ }^{15-20}$ From ellipsometric measurements of the oxide thickness on GaAs exposed to air at room temperature over time, it has been determined that the native oxide of GaAs grows at a logarithmic rate given by ${ }^{18}$

$$
d(\AA)=5.969+5.929 \log [t(\min )]
$$

Even after $10^{6} \min (\approx 2$ years), the oxide thickness measured only $42 \AA$. Measurements of oxide thickness uniformity and chemical stoichiometry have shown that the initial surface oxide $(<\mathbf{1 0 0} \AA)$ is uniform and chemically homogeneous, yielding $\mathrm{Ga}$ to As ratios of approximately $1: 1$ in the oxide phase. ${ }^{20}$ Therefore, uniformity problems that may occur can be avoided by minimizing the oxide 
layer thickness to less than $100 \AA . \mathrm{H}_{2} \mathrm{O}_{2}$ is a well-known oxidizer which forms a stable, native oxide of $\mathrm{GaAs},{ }^{15}$ and is used in most GaAs wet chemical etchants. ${ }^{15,17,21-23}$ Although timed oxidation curves of GaAs from exposure to $\mathrm{H}_{2} \mathrm{O}_{2}$ at room temperature may not be available, other researchers have measured an oxide thickness of $115 \AA$ after soaking a $\mathrm{GaAs}$ sample in $\mathrm{H}_{2} \mathrm{O}_{2}$ for 6 days at room temperature. ${ }^{17}$ Even soaking $\mathrm{GaAs}$ in boiling $\mathrm{H}_{2} \mathrm{O}_{2}$ forms only relatively thin oxides of $150 \AA . .^{15}$ Therefore, it is believed that $\mathrm{H}_{2} \mathrm{O}_{2}$ oxidizes $\mathrm{GaAs}$ with a logarithmic growth rate sufficiently slow to be considered as a self-limiting (diffusion-limited) process.

The final step in the digital etching process is to selectively remove the oxide layer formed on the GaAs surface without etching the unreacted GaAs material underneath. This can be easily accomplished by using various acids or bases. The use of acids or bases (without hydrogen peroxide) as an oxide remover and for surface cleaning of GaAs is well known in semiconductor device processing. ${ }^{14,23}$

\section{Experimental Digital Etching}

Several wet chemical digital etching techniques were attempted to determine one that provided consistent and reproducible results. An important step in the etching process is to completely separate the chemicals used for each part of the digital etch step (oxidation step and oxide etching step). That is, it is necessary to completely rinse the $\mathrm{H}_{2} \mathrm{O}_{2}$ before applying the acid, and vice versa. Residue of either $\mathrm{H}_{2} \mathrm{O}_{2}$ or acid on the $\mathrm{GaAs}$ wafer will mix with the next application of acid or $\mathrm{H}_{2} \mathrm{O}_{2}$ and provide a normal acid: $\mathrm{H}_{2} \mathrm{O}_{2}$ etchant that destroys the controlled, self-limiting digital etching process. Because $\mathrm{H}_{2} \mathrm{O}_{2}$ and many acids contain water, the use of deionized water $\left(\mathrm{DI} \mathrm{H}_{2} \mathrm{O}\right)$ was selected to provide the necessary rinsing between each step. To prevent dilution of the chemical agents, an $\mathrm{N}_{2}$ blow dry is used to remove any water remaining after rinsing

A new method was developed to provide separately fresh oxidizing and etching solutions to the sample during each etch step to minimize chemical cross contamination. Since contamination due to incomplete rinsing must be eliminated to maintain the digital etching chemistry, a photoresist spinner was modified to perform the digital etching procedure. The modification of the photoresist spinner consisted of replacing exposed metal parts (wafer chuck, vacuum shaft, and spinner baseplate) with oxidizer and acid resistant high density polypropylene machined to original specifications. With the spinner, fresh oxidizing and etching solutions can be sprayed from above onto the sample during each etch step. The spinning motion removes the applied solution quickly, and allows the application of a continuously fresh stream of solution. $\mathrm{DI} \mathrm{H}_{2} \mathrm{O}$ rinsing of the wafer can also take place while spinning, providing a continuously fresh water stream to remove the oxidizing and etching solutions. In this manner, fresh solutions of $\mathrm{H}_{2} \mathrm{O}_{2}$, acid, and DI $\mathrm{H}_{2} \mathrm{O}$ are applied to the sample during the digital etch, thereby eliminating cross contamination between $\mathrm{H}_{2} \mathrm{O}_{2}$ and the acid.

Process development has demonstrated that successful digital etching requires the use of uncontaminated oxidizing and etching solutions with complete rinsing between the oxidizing and acid etching steps. Spin rinsing with fresh DI $\mathrm{H}_{2} \mathrm{O}$ for $15 \mathrm{~s}$ at $1000 \mathrm{rpm}$ was found to be sufficient to remove both the oxidizing and etching solutions from the wafer before applying the next solution in the digital etch process. However, it was determined that spinning the wafer during applications of the oxidizing and etching solutions was not necessary, as soaking the wafer during these steps was determined to be sufficient. The measured digital etch rates of this soak and spin rinsing method are equivalent to those obtained using the continuous spin technique. Soaking is desirable because it provides a large reservoir of solution to perform the necessary oxidation and etching without depleting the solution. Because these experiments were performed manually, the static chemical soak and spin rinsing technique was used to maintain repeatability and reproducibility, as it was difficult to insure complete coverage with manual spraying, whereas a static flood was easy to accomplish and maintain during the given soak times. The digital etching experiments conducted in this work used a combined chemical soak and spin rinsing procedure as outlined in Table I.

\section{Etch Depth Measurements}

Two depth profiling techniques were used to measure and verify the digital etch rate of GaAs. Since digital wet etching results in a small etch depth for each digital etch cycle performed $(\approx 15 \AA /$ cycle), numerous etch cycles may be necessary to provide sufficient thickness change for accurate measurement. Although the mechanical profilometer has a rated resolution of $1 \AA$ it can only accurately measure about $150 \AA$ in relative etch depth change or larger, which requires ten or more digital etching cycles. However, even this depth approaches the accuracy of mechanical profilometers. Other measurement techniques which are capable of measuring smaller etch depths than a mechanical profilometer include atomic force microscopy (AFM) and the Hall measurement technique. The AFM and mechanical profilometer measurements require masking of the sample surface because direct etch depth measurements are made by comparing the etched surface depth relative to the unetched surface. Masking is accomplished using standard lithographic techniques to open trenches in the photoresist. For these experiments, a 100 $\mu \mathrm{m}$ wide trench was used for mechanical profilometer measurements.

Using a sensitive Hall effect measurement system, the depth of a given semiconductor surface can be indirectly measured by comparing the difference in the electrical parameters measured by Hall before and after etching. The Hall technique does not require masking of the sample surface, and measures the average change in depth across relatively large surfaces $\left(e . g ., 1 \mathrm{~cm}^{2}\right)$. Since the Hall measurement technique uses an electrical and not a mechanical measurement, errors due to mechanical vibration noises are eliminated and the resolution of the etch depth measurement is limited only by errors from the electrical measurement system. As an example, from accuracy and signal-to-noise considerations alone, the Hall technique can potentially resolve thickness changes in less than $1 \AA$ in a $500 \AA$ thick GaAs layer doped at the $10^{18} \mathrm{~cm}^{-3}$ level. However, other factors may degrade this high resolution.

To use the Hall technique, several semiconductor wafers were prepared by growing 350 to $2000 \AA$ thick layers of heavily n-type Si doped $\left(5 \times 10^{18} \mathrm{~cm}^{-3}\right) \mathrm{GaAs}$ on $(100)$ semi-insulating GaAs substrates using molecular beam epitaxy (MBE). The layer thicknesses are thin to maximize the change in Hall parameters after digital etching. Since

Table I. Experimental procedure used to perform a single wet chemical digital etching cycle.

\begin{tabular}{|c|c|c|c|c|}
\hline Step & Procedure & Chemical used & Application time (s) & Spin speed (rpm) \\
\hline A & $\begin{array}{l}\text { Apply and soak wafer with oxidizing agent } \\
\text { Rinse away oxidizing agent } \\
\text { Blow dry to remove rinsing agent }\end{array}$ & $\underset{\mathrm{N}_{2}}{\mathrm{H}_{2} \mathrm{O}_{2}}$ & $\begin{array}{l}15 \text { to } 120 \\
15 \\
5\end{array}$ & $\begin{array}{c}0 \\
1000 \\
1000\end{array}$ \\
\hline B & $\begin{array}{l}\text { Apply and soak wafer with oxide removing agent } \\
\text { Rinse away oxide removing agent } \\
\text { Blow dry to remove rinsing agent }\end{array}$ & $\begin{array}{l}\text { Acid } \\
\text { DI } \mathrm{H}_{2} \mathrm{O} \\
\mathrm{N}_{2}\end{array}$ & $\begin{array}{l}15 \text { to } 120 \\
15 \\
5\end{array}$ & $\begin{array}{c}0 \\
1000 \\
1000\end{array}$ \\
\hline
\end{tabular}


the underlying substrate is semi-insulating, the electrical properties measured by the Hall technique are only due to the n-type grown layer. Hall measurements are performed on $6 \times 6 \mathrm{~mm}$ pieces from these wafers to determine the Hall resistance, mobility, and doping concentration. From these measurements the change in thickness (loss of material) due to etching can be calculated even though the exact thickness $(t)$ of the sample cannot be determined.

This change in thickness $(\Delta t)$ in terms of the differences between Hall measured values is calculated using ${ }^{24}$

$$
\Delta t=t_{2}-t_{1}=\frac{\mu_{n_{2}} n_{\square_{2}}-\mu_{n_{1}} n_{\square_{1}}}{\mu_{n_{0}} n_{0}}
$$

where $n_{\circ}$ and $\mu_{n_{0}}$ are the initial volume carrier concentration $\left(\mathrm{cm}^{-3}\right)$ and mobility $\left(\mathrm{cm}^{2} / \mathrm{V} \mathrm{s}\right)$ measured before any etching of the sample occurs, and $n_{\square}$ and $\mu_{n}$ are the sheet carrier concentration $\left(\mathrm{cm}^{-2}\right)$ and mobility $\left(\mathrm{cm}^{2} / \mathrm{V} \mathrm{s}\right)$ of the sample measured by the Hall technique just prior to etching $\left(n_{\square 1}, \mu_{n_{1}}\right)$ and after etching $\left(n_{\square 2}, \mu_{n_{2}}\right)$. An accurate determination of the volume carrier concentration $\left(n_{0}\right)$ requires MBE growths of identical material layers of different original thicknesses in order to correct for surface and interface depletion effects. ${ }^{24}$ Once $n_{0}$ and $\mu_{n 0}$ have been measured, the thickness of the sample prior to etching does not need to be known because the equation calculates the change in thickness $\left(t_{2}-t_{1}\right)$ before and after etching. The sample can be etched repeatedly and the change in thickness calculated until the n-type layer becomes too thin for accurate Hall measurement. The details of this new Hall technique used to measure changes in semiconductor thickness are presented in Ref. 24.

\section{Digital Etch Experimental Results}

The experimental digital etching procedure used for these experiments is outlined in Table I. A single digital etching cycle consists of both steps $A$ and $B$, which are repeated to obtain a desired etch depth. Experiments were conducted to determine a digital etching technique using wet chemicals.

The experiments consisted of (1) oxide removal chemical selection in digital etching, (2) oxidation chemical selection $\left(\mathrm{H}_{2} \mathrm{O}_{2}\right.$ or $\left.\mathrm{H}_{2} \mathrm{O}\right)$ in digital etching, (3) digital etch rate dependence on the number of digital etch cycles, and (4) oxidation and oxide removal dependence on chemical application soak times. All digital etching experiments were conducted in a climate-controlled clean room at room temperature $\left(20^{\circ} \mathrm{C}\right)$ under yellow fluorescent lighting to prevent unwanted exposure of photoresist used for mechanical profilometer measurements. All experiments used a ten cycle digital etch except for the case (No. 3) where the number of etch cycles was varied. Also, all experiments used 1 min soak times for both steps $A$ and $B$, except for the experiment (No. 4) which varied the soak times of the oxidizing agent and the oxide removal agent. Finally, except where noted, the Hall technique was used to measure the etch depths obtained from these experiments.

The first experiment used six different chemical solutions as the oxide etchant in the digital etch procedure. These solutions consisted of hydrochloric acid $(\mathrm{HCl}), 1 \mathrm{M}$ citric acid, phosphoric acid $\left(\mathrm{H}_{3} \mathrm{PO}_{4}\right)$, sulfuric acid $\left(\mathrm{H}_{2} \mathrm{SO}_{4}\right)$, buffered oxide etch (BOE), and ammonium hydroxide
Table II. Digital etch rate dependence on acid or base using a 10 cycle digital etch step repetition with 1 min acid soaks and 1 min $\mathrm{H}_{2} \mathrm{O}_{2}$ soaks.

Acid or base

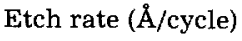

$\mathrm{HCl}: \mathrm{H}_{2} \mathrm{O}(1: 1)$
$1 M$ Citric acid $\left(\mathrm{C}_{6} \mathrm{H}_{8} \mathrm{O}_{7}\right)$
$\mathrm{H}_{3} \mathrm{PO}_{4}: \mathrm{H}_{2} \mathrm{O}(1: 4)$
$\mathrm{H}_{2} \mathrm{SO}_{4}: \mathrm{H}_{2} \mathrm{O}(1: 10)$
$\mathrm{HF}^{\mathrm{NH}} \mathrm{H}_{4} \mathrm{~F}[\mathrm{BOE}](1: 7)$
$\mathrm{NH}_{4} \mathrm{OH}: \mathrm{H}_{2} \mathrm{O}(1: 1)$
15.5 14.3 12.6 11.4 15.5 29.6

$\left(\mathrm{NH}_{4} \mathrm{OH}\right)$. The Hall measurements showed that any of these acids removed the GaAs-oxide and gave a fairly constant etch depth and calculated etch rate [Table II]. The digital etch rate was calculated using

Digital etch rate $(\AA /$ cycle)

$$
=\frac{\text { Measured etch depth }(\AA)}{\text { Number of digital etch cycles }}
$$

However, $\mathrm{NH}_{4} \mathrm{OH}$ produced an etch rate double that of the acids. Some acids and bases are known to be oxidizing and oxide removing agents such as $\mathrm{HNO}_{3}$ acid, ${ }^{25,26}$ therefore, $\mathrm{NH}_{4} \mathrm{OH}$ may be a partial oxidizing agent as well as an oxide removal agent which would account for this larger etch rate. A second experiment was performed substituting $\mathrm{DI} \mathrm{H}_{2} \mathrm{O}$ for $\mathrm{H}_{2} \mathrm{O}_{2}$ as the oxidizing agent and using $\mathrm{HCl}$, citric acid, or $\mathrm{NH}_{4} \mathrm{OH}$ as the oxide removing agent. Since $\mathrm{H}_{2} \mathrm{O}$ can oxidize GaAs, ${ }^{15,17}$ it is important to see if $\mathrm{H}_{2} \mathrm{O}$ present in the wet chemical digital etching process would significantly oxidize GaAs during the given application soak times. Because the acids incorporate water and if GaAs is significantly oxidized by water, then a wet chemical digital etching technique would not be possible. However, this second experiment gave total etch depths (not the etch rate) of $4.2 \AA$ with $\mathrm{HCl}, 13.8 \AA$ with citric acid, and $57.4 \AA$ with $\mathrm{NH}_{4} \mathrm{OH}$ after performing a ten cycle digital etch. From this experiment, it is concluded that $\mathrm{H}_{2} \mathrm{O}$ does not act as a significant oxidizing agent for GaAs when applied for $1 \mathrm{~min}$ soak times. It is believed that the small etch depths measured for the acids are attributable to the removal of native oxide present on GaAs prior to digital etching. ${ }^{15,16,18}$ The results obtained from the $\mathrm{DI} \mathrm{H}_{2} \mathrm{O}$ and $\mathrm{NH}_{4} \mathrm{OH}$ ten cycle digital etch process showed definite etching with a measured etch rate of $5.74 \AA$ /cycle. When compared to the etch rates obtained when using $\mathrm{H}_{2} \mathrm{O}_{2}$ with $\mathrm{NH}_{4} \mathrm{OH}$, it can be concluded that $\mathrm{NH}_{4} \mathrm{OH}$ is also oxidizing the $\mathrm{GaAs}$ surface resulting in larger etch depths and etch rates.

The last three experiments were conducted using $\mathrm{HCl}: \mathrm{H}_{2} \mathrm{O}(1: 1)$ as the oxide removing agent. $\mathrm{HCl}$ acid was selected because it appears to have the lowest chemical interaction with GaAs for digital etching, yielding a $4.2 \AA$ etch depth after ten cycles with water as the oxidizing agent. The third experiment varied the number of digital etch cycles from 5 to 30 . The average etch depth and calculated etch rate values are presented in Table III and shown graphically in Fig. 1. Increasing the number of digital etch cycles produced larger etch depths, but the etch rate as calculated by Eq. 3 remained relatively constant. A

\begin{tabular}{|c|c|c|c|c|}
\hline \multirow[b]{2}{*}{$\begin{array}{l}\text { No. of digital } \\
\text { etch cycles }\end{array}$} & \multicolumn{2}{|c|}{ Hall technique } & \multicolumn{2}{|c|}{ Mechanical profilometer } \\
\hline & $\begin{array}{l}\text { Average measured } \\
\text { etch depth }(\AA)\end{array}$ & $\begin{array}{l}\text { Calculated etch } \\
\text { rate }(\AA / \text { cycle })\end{array}$ & $\begin{array}{l}\text { Average measured } \\
\text { etch depth }(\AA)\end{array}$ & $\begin{array}{l}\text { Calculated etch } \\
\text { rate }(\AA / \text { cycle })\end{array}$ \\
\hline $\begin{array}{r}5 \\
9 \\
10 \\
15 \\
20 \\
30\end{array}$ & $\begin{array}{r}79 \\
132 \\
155 \\
231 \\
328 \\
509\end{array}$ & $\begin{array}{l}15.9 \\
14.7 \\
15.5 \\
15.4 \\
16.4 \\
17.0\end{array}$ & $\begin{array}{l}- \\
\overline{158} \\
240 \\
326 \\
462\end{array}$ & $\begin{array}{l}\overline{-} \\
\overline{15.8} \\
16.0 \\
16.3 \\
15.4\end{array}$ \\
\hline
\end{tabular}

Table III. Digital etch rate dependence on the number of digital etch cycles performed using 1 min HCl: $\mathrm{H}_{2} \mathrm{O}(1: 1)$ soaks and 1 min $\mathrm{H}_{2} \mathrm{O}_{2}$ soaks. 


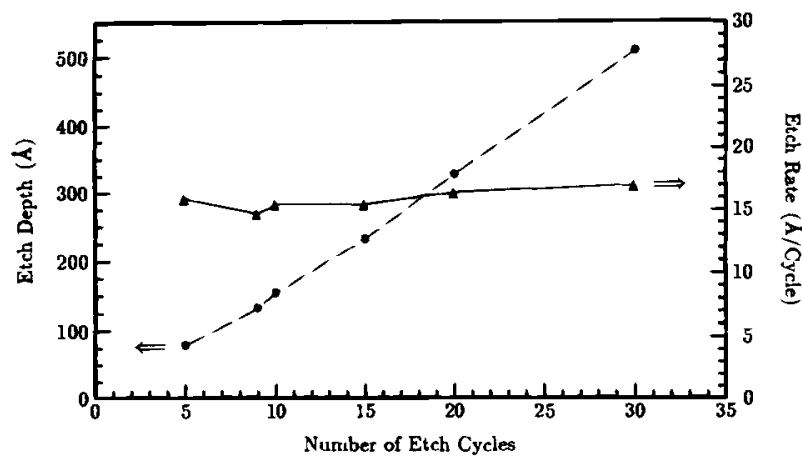

Fig. 1. Graphical comparison of measured (O) etch depth (left $y$ axis) and calculated ( $\Delta$ ) etch rate per digital etch cycle (right $y$ axis) dependence on number of digital etch cycles performed. Experimental data used in this plot are from Hall measurements shown in Table III.

useful feature of the digital etch process is that the etch depth is directly proportional to the number of etch cycles executed. With a digital etch process, the final etch depth is determined not by the time length of the etch as in standard etching, but instead by the number of digital etch cycles performed. Therefore, the amount of material etched is always a multiple of the single-cycle etch depth. Figure 1 graphically displays the linear relationship between the etch depth and the number of etch cycles, demonstrating that the etch rate remains constant for all etch cycles.

The fourth digital etching experiment varied the $\mathrm{H}_{2} \mathrm{O}_{2}$ and $\mathrm{HCl}$ soak times. First, the $\mathrm{H}_{2} \mathrm{O}_{2}$ soak times were kept constant at $1 \mathrm{~min}$, while the $\mathrm{HCl}$ soak time was varied from $15 \mathrm{~s}$ to $120 \mathrm{~s}$ [column 2 of Table IV]. Then, the $\mathrm{HCl}$ soak times were held constant at 1 min while the $\mathrm{H}_{2} \mathrm{O}_{2}$ soak time was varied from $15 \mathrm{~s}$ to $120 \mathrm{~s}$ [column 3 of Table IV]. Finally, both soak times were set equal and varied at the same rate, resulting in etch time variations from very short etch cycles to very long etch cycles [column 4 of Table IV]. Because this digital etching procedure was performed manually, and short soak times may involve significant timing errors, soak times of $15 \mathrm{~s}$ or greater were used. The purpose of this experiment was to determine the minimum soak times needed to oxidize the GaAs surface and remove the oxide layer. In standard etching techniques, the etch rates $(\AA / / s)$ are dependent on time, such that longer etch times result in deeper etch depths. Digital etching has etch rates ( $\AA$ /cycle) that are independent of etch times, so that the etch depth is only dependent on the number of digital etch cycles performed. However, this is only true when each soak time is longer than the minimum time needed to oxidize the semiconductor layer or to remove this oxide layer. The purpose of this experiment was to determine the minimum soak times necessary in order to have a usable digital etching technique. However, the results here indicate that soak times as short as $15 \mathrm{~s}$ are still sufficient to perform a good digital etch. The results from Table IV show that there is no significant variation in the etch depths or the calculated etch rates for all soak time variations from 15 to $120 \mathrm{~s}$. Therefore, the oxide formation and oxide removal occur in less than $15 \mathrm{~s}$. Because longer soak times do not increase the overall etch rate, this process is self-limiting in terms of both oxide layer formation and oxide layer removal. That is, longer chemical soak times do not result in larger etch depths, and have no effect on the overall etch rate. With an automated digital etching station where precise control of soak time can be achieved, soak times of less than $15 \mathrm{~s}$ would be possible, and the time to perform this digital etching process might decrease. An automated digital etching station can be used to determine the minimum soak times necessary to maintain a constant digital etch rate, such that an optimized digital etching process can be developed.
Table IV. Digital etch rate dependence on digital erch soak time using a ten cycle digital etch repelition.

\begin{tabular}{lccc}
\hline & \multicolumn{3}{c}{ Digital etch rate $(\AA /$ cycle $)$} \\
\cline { 2 - 4 } $\begin{array}{l}\text { Variable } \\
\text { Chemical }\end{array}$ & $60 \mathrm{~s} \mathrm{H}_{2} \mathrm{O}_{2}$ & $\times \mathrm{s} \mathrm{H}_{2} \mathrm{O}_{2}$ & $\times \mathrm{s} \mathrm{H}_{2} \mathrm{O}_{2}$ \\
soak time $(\mathrm{s})$ & $\times \mathrm{s} \mathrm{HCl}^{2}$ & $60 \mathrm{~s} \mathrm{HCl}^{\mathrm{a}}$ & $\times \mathrm{s} \mathrm{HCl}^{\mathrm{a}}$ \\
\hline 7 & - & - & 14.2 \\
15 & 15.9 & 15.7 & 14.4 \\
30 & 14.4 & 19.4 & 15.7 \\
45 & 15.2 & 17.1 & 17.7 \\
60 & 15.5 & 15.5 & 15.5 \\
90 & 15.2 & 14.6 & 16.3 \\
120 & 14.1 & 16.0 & 15.6 \\
\hline
\end{tabular}

${ }^{\mathrm{a}} \mathrm{HCl}$ solution consists of $\mathrm{HCl}: \mathrm{H}_{2} \mathrm{O}(1: 1)$.

\section{Analysis and Conclusions}

For the soak times considered in this work, the amount of material etched during a single digital etch cycle does not depend on the length of soak time of the $\mathrm{H}_{2} \mathrm{O}_{2}$ or acid, but rather on the number of digital etch cycles performed. The thickness removed by one digital etch cycle equals the amount of semiconductor material consumed in the oxidation step. Oxidation of $\mathrm{GaAs}$ with $\mathrm{H}_{2} \mathrm{O}_{2}$ is a self-limiting process that provides a constant oxide layer thickness of about $15 \AA$ for $\mathrm{H}_{2} \mathrm{O}_{2}$ soak times from 15 to $120 \mathrm{~s}$. For a constant digital etch rate, it is important to select an acid or base that removes the oxide layer without further oxidizing the GaAs surface, as such oxidation causes unpredictable etch rates. Therefore, acids or bases that oxidize GaAs such as $\mathrm{HNO}_{3}$ and $\mathrm{NH}_{4} \mathrm{OH}$ are not suitable for wet chemical digital etching.

The results from Tables III and IV represent the average values taken from several experimental trials (from 4 to 12) for each parameter varied. The calculated etch rates as given by Tables III and IV compare favorably and remain relatively constant at approximately 15 A for all the parameters varied. Although the bulk of individual measurements were centered around these averages, there were a few extreme measurements as low as $11 \AA$ /cycle to as high as $20 \AA$ /cycle. These variations may be attributed to measurement errors and experimental errors due to the manual nature of the experiments conducted. It is believed that such variations will be minimized by automating the digital etch process.

Initial atomic force microscopy measurements of digital etch depths of $\mathrm{GaAs}$ in photoresist trench openings having widths of 15,5 , and $0.2 \mu \mathrm{m}$ are in general agreement with Hall technique and mechanical profilometer measurements. Determination of any digital etch depth dependence on exposed surface opening (photoresist trench width) as measured by atomic force microscopy are currently underway. Finally, AFM measurements of surface roughness will be performed to determine the change in surface roughness from using the digital etching technique.

Future work includes automation of the wet chemical digital etching process equipment to minimize manual timing errors and to provide longer etching cycles (e.g., 50 to 100 cycles). The automated digital etching station will also be assessed for its potential use in a manufacturable process. Other future research will focus on digital etching of GaAs and other semiconductor materials as a function of doping type, carrier concentration, operating temperature, and chemical solution concentration.

\section{Acknowledgments}

The authors wish to thank Tim Cooper for performing the numerous Hall measurements, Jeff Brown for assisting us with the atomic force microscopy system, and Gary McCoy, Robert Kemerley, and Linda Fleck for their support. G. C. DeS. was with the National Research Council and the Northeast Consortium for Engineering Education at Wright Laboratory during the earlier stages of this work, and wishes to express his appreciation for their support. 
Manuscript submitted April 29, 1996; revised manuscript received Aug. 9, 1996.

Dr. Bozada assisted in meeting the publication costs of this article.

\section{REFERENCES}

1. K. B. Chough, T. Y. Chang, M. D. Feuer, N. J. Sauer, and B. Lalevic, IEEE Electron Device Lett., EDL-13, 451 (1992).

2. F. Hirler, R. Küchler, R. Strenz, G. Abstreiter, G. Böhm, J. Smoliner, G. Tränkle, and G. Weimann, Surf. Sci., 263, 536 (1992).

3. G. C. DeSalvo, J. L. Ebel, C. A. Bozada, J. P. Barrette C. L. Cerny, R. W. Dettmer, J. K. Gillespie, C. K. Havasy, T. J. Jenkins, K. Nakano, C. I. Pettiford, T K. Quach, J. S. Sewell, and D. G. Via, in Proceedings of the 1996 International Conference on GaAs Manufacturing Technology, p. 29 (1996).

4. T. Meguro, M. Hamagaki, S. Modaressi, T. Hara, Y. Aoyagi, M. Ishii, and Y. Yamamoto, Appl. Phys. Lett., 56, $1552(1990)$

5. T. Meguro, M. Ishii, H. Kodama, M. Hamagaki, T. Hara, Y. Yamamoto, and Y. Aoyagi, Jpn. J. Appl. Phys., 29, 2216 (1990).

6. Y. Aoyagi, K. Shinmura, K. Kawasaki, T. Tomoko, K. Gamo, S. Namba, and I. Nakamoto, Appl. Phys. Lett., 60, 968 (1992).

7. M. Ishii, T. Meguro, H. Kodama, Y. Yamamoto, Y Aoyagi, Jpn. J. Appl. Phys., 31, 2212 (1992).

8. T. Matsuura, J. Murota, and Y. Sawada, Appl. Phys. Lett., 63, 2803 (1993).
9. T. Meguro, M. Ishii, H. Kodama, $Y$ Yamamoto, $K$ Gamo, and Y. Aoyagi, Thin Solid Films, 225, 136 (1993)

10. P. A. Maki and D. J. Ehrlich, Appl Phys. Lett, 55, 91 (1989).

11. M. Ishii, T. Meguro, K. Gamo, T. Sugano, and Y Aoyagi, Jpn. J. Appl. Phys., 32, 6178 (1993).

12. S. Takatani and T. Kikawa, Appl. Phys. Lett., 65, 2585 (1994).

13. F. Djamdji and R. Blunt, Mater. Sci. Engr, B20, 77 (1993).

14. Gallium Arsenide Materials, Devices, and Circuits, M J. Howes and D. V. Morgan, Editors, p. 123-132, John Wiley \& Sons, Inc., New York (1985).

15. B. Schwartz, CRC Critical Reviews in Solid State Sciences, 609 (1975)

16. S. S. Cohen, Thin Solid Films, 104, 361 (1983)

17. B. Schwartz, This Journal, 118, 657 (1971).

18. F. Lukes, Surf. Sci., 30, 91 (1972).

19. B. J. Sealy and P. L. F Hemment, Thin Solid Films, 22, S39 (1974).

20. G. Lucovsky, J. Vac. Sci. Technol., 19, 456 (1981)

21. W. Kern, RCA Rev., 39, 278 (1978)

22. D. W. Shaw, This Journal, 128, 874 (1981)

23. R. E. Williams, Gallium Arsenide Processing Techniques, pp. 93-122, Artech House, Dedham, MA, (1984).

24. G. C. DeSalvo, D. C. Look, C. A. Bozada, and J. L. Ebel, J. Appl. Phys., To be published, Jan. 1997

25. D. J. Stirland and B. W. Straghan, Thin Solid Films, 31, 139 (1976).

26. S. Adachi and K. Oe, This Journal, 130, 2427 (1983).

\title{
Comparison of $\mathrm{ICl}$ and $\mathrm{IBr}$ Plasma Chemistries for Etching of InGaAlP Alloys
}

\author{
J. Hong, " J. W. Lee, E. S. Lambers, C. R. Abernathy,"* and S. J. Pearton*** \\ Department of Materials Science and Engineering, University of Florida, Gainesville, Florida 32611, USA \\ C. Constantine
}

Plasma Therm IP, St. Petersburg, Florida 33716, USA

W. S. Hobson**

Bell Laboratories, Lucent Technologies, Murray Hill, New Jersey 07974, USA

\section{ABSTRACT}

$\mathrm{ICl}$ and $\mathrm{IBr}$ provide rapid etching of the ternary alloys InGaP, AlInP, and AlGaP under electron cyclotron resonance conditions. The rates are almost independent of microwave power in the range 400 to $1000 \mathrm{~W}$, with typical values of $-1.5 \mu \mathrm{m} / \mathrm{min}$ with ICl/Ar and $\sim 0.4 \mu \mathrm{m} / \mathrm{min}$ with IBr/Ar. At low microwave powers $(\leq 750 \mathrm{~W})$, the etched surface morphologies are quite smooth and there is little degradation of photoresist masks. High Al content $\mathrm{Al}_{x} \mathrm{Ga}_{1-x} \mathrm{P}(x \geq 0.7)$ alloys appear to be good candidates as etchstop layers in InGaAlP device structures when using these plasma chemistries.

\section{Introduction}

The two main heterostructure material systems for compound semiconductor diode lasers and light-emitting diodes are InGaAsP and InGaAlP. ${ }^{\prime}$ The only universal plasma chemistry for etching these materials at room temperature is $\mathrm{CH}_{4} / \mathrm{H}_{2},{ }^{2}$ which has numerous disadvantages, especially for InGaAIP, including low etch rates, hydrogen passivation of dopants, and extensive deposition of polymer in the mask material. ${ }^{3}$ Two potential classes of plasma chemistry that have not received much attention are those based on $\mathrm{I}_{2}$ and $\mathrm{Br}_{2}{ }^{4-8}$ In particular, iodine chemistries are attractive for efficient removal of In-containing materials. ${ }^{9,10}$ Table I compares the boiling points of the expected etch products for the ternary alloys InGaP, AlInP, and

* Electrochemical Society Student Member

** Electrochemical Society Active Member.

*** Electrochemical Society Fellow.
AlGaP, which are the most common components of devices based on the InGaAlP system. ${ }^{11}$ While the volatility under ion-assisted etching conditions is obviously the most important factor in determining etch rates, the boiling points of the potential products give some clues as to the possible efficiency of the gas chemistry. It is clear from Table I that a plasma chemistry containing both $\mathrm{I}_{2}$ and $\mathrm{Cl}_{2}$ should be a universal etchant for III-V materials.

The compounds $\mathrm{ICl}$ and $\mathrm{IBr}$ are available as crystalline solids, with melting points of 27.2 and $50^{\circ} \mathrm{C}$, respectively. ICl boils at $97.4^{\circ} \mathrm{C}$, while IBr sublimes and therefore at moderate temperatures one can easily obtain gas flow rates sufficient for dry etching processes. In this paper we report on the use of $\mathrm{ICl} / \mathrm{Ar}$ and $\mathrm{IBr} / \mathrm{Ar}$ electron cyclotron resonance (ECR) plasma etching for patterning InGaP, AlInP, and AlGaP. Both gas chemistries are shown to be capable of smooth high-rate pattern transfer into these materials. The etch rates with $\mathrm{ICl}$ are up to five times faster than $\mathrm{Cl}_{2}$ 